Research Article

\title{
Synthesis of Hydrophilic Sulfur-Containing Adsorbents for Noble Metals Having Thiocarbonyl Group Based on a Methacrylate Bearing Dithiocarbonate Moieties
}

\author{
Haruki Kinemuchi and Bungo Ochiai ii \\ Department of Chemistry and Chemical Engineering, Faculty of Engineering, Yamagata University, 4-3-16 Jonan, Yonezawa, \\ Yamagata 992-8510, Japan \\ Correspondence should be addressed to Bungo Ochiai; ochiai@yz.yamagata-u.ac.jp
}

Received 27 June 2017; Accepted 1 January 2018; Published 1 March 2018

Academic Editor: Santiago Garcia-Granda

Copyright (c) 2018 Haruki Kinemuchi and Bungo Ochiai. This is an open access article distributed under the Creative Commons Attribution License, which permits unrestricted use, distribution, and reproduction in any medium, provided the original work is properly cited.

Novel hydrophilic sulfur-containing adsorbents for noble metals were prepared by the radical terpolymerization of a methacrylate bearing dithiocarbonate moieties (DTCMMA), hydrophilic monomers, and a cross-linker. The resulting adsorbents efficiently and selectively adsorbed noble metals ( $\mathrm{Au}, \mathrm{Ag}$, and $\mathrm{Pd}$ ) from various multielement aqueous solutions at room temperature owing to the thiocarbonyl group having high affinity toward noble metals. The metal adsorption by the adsorbents was proceeded by simple mixing followed by filtration. The noble metal selectivity of the adsorbent obtained from DTCMMA and $N$-isopropylacrylamide was higher than that of the adsorbent obtained from DTCMMA and N,N-dimethylacrylamide due to the lower nonspecific adsorption.

\section{Introduction}

Noble metals such as $\mathrm{Au}, \mathrm{Pd}$, and $\mathrm{Ag}$ are essential in the modern life and applied in various fields such as jewelry [1], synthetic catalysts [2-5], and materials for electronic industry [6]. The amounts of noble metals in mines are inherently very low, and the recent increase in their use is shortening their reserves to production ratios. Therefore, recovery and reuse of these metals from various used materials is very essential. For example, the recycling from industrial wastewater and urban mines is promising owing to the high amounts and contents.

Typical methods for collection of noble metals from water are solvent extraction [7-12], adsorption [13-31], and electrochemical processes [32]. The collection by adsorption is advantageous owing to its low cost, safety, and high efficiency. By contrast, solvent extraction requires organic solvents, lots of eluents, and in some cases supercritical eluents to attain high extraction efficiency. As a result, tremendous amounts of wastes are produced. Electrochemical processes require a troublesome procedure to scrape off the deposited metals on the electrode. Adsorbents bearing sulfur substituents are one of the most examined adsorption agents for noble metals owing to the excellent affinity of sulfur toward soft cations due to the soft Lewis basicity and the facileness of its introduction into various organic structures [30, 33-37]. Dithiocarbamic acids are the most popular sulfur adsorbents for heavy metals [38]. Dithiocarbamic acids effectively adsorb various metals, but the selectivity of the metal adsorption is low. The emission of toxic carbon disulfide is also a severe problem, although the emission rate is slow [39]. Adsorbents based on thiols and thiocarbonyl moieties are advantageous by eliminating the possibility of the leakage of sulfur compounds such as carbon disulfide. Thiols are effective scavengers for various metals by forming stable thiolates [40-46]. However, thiol groups are susceptible to oxygen-converting thiols into disulfides via oxidative coupling [44]. Thiocarbonyl moieties such as thioamide [26-30, 47-53], thiourethane [31, 33, 35, 37], and thiourea $[11,25,54-60]$ have also been examined as stable adsorbents. We also have found that a polymer bearing $N, N$-dialkylthiourethane moieties has high adsorption ability to $\mathrm{Pd}$ and $\mathrm{Au}$, but the adsorption from aqueous solutions only proceeded in the presence of organic solvents 
such as chloroform due to the hydrophobic nature of the backbone [35]. Although these adsorbents bearing thiocarbonyl moieties certainly adsorb metals from aqueous or organic solvents, the effect of the structures adjacent to thiocarbonyl groups is still unclear.

In this study, we designed a hydrophilic adsorbent bearing thiocarbonyl moieties for selective adsorption of noble metals in an organic solvent free manner. As the source for thiocarbonyl groups, we focused on a methacrylate bearing dithiocarbonate moieties (5-(methacryloyloxy) methyl-1,3-oxathiolane-2-thione, DTCMMA) [61], which can be prepared via a simple reaction of glycidyl methacrylate with carbon disulfide. In order to adsorb noble metals from water in a facile manner, DTCMMA was copolymerized with hydrophilic monomers and a cross-linker to make the adsorbents swellable and insoluble. Selectivity of the adsorption was evaluated using three solutions containing multiple metal ions.

\section{Materials and Methods}

2.1. Materials. DTCMMA was prepared according to the reported procedure [61]. $\mathrm{N}$-isopropylacrylamide (NIPAM) (Wako Pure Chemical, >98.0\%) was purified by recrystallization from a mixed solvent of diethyl ether and $n$-hexane. $\mathrm{N}, \mathrm{N}$-dimethylacrylamide (DMAA) (Kanto Chemical, >97.0\%) was dried over calcium hydride and distilled under reduced pressure. Dehydrated dimethyl sulfoxide (DMSO) (Wako Pure Chemical, >99.0\%), $N, N^{\prime}$-methylenebisacrylamide (MBAA) (Wako Pure Chemical, >97.0\%), 2,2'-azobis(isobutyronitrile) (AIBN) (Tokyo Chemical Industry, $>98.0 \%$ ), palladium(II) chloride (Wako Pure Chemical, $>99.0 \%$ ), anhydrous copper(II) chloride (Wako Pure Chemical, $>99.0 \%$ ), nitric acid (Wako Pure Chemical, concentration: 60-61\%), and hydrochloric acid (Kanto Chemical, concentration: 35.0-37.0\%) were commercially available and used as received. Multielement solutions containing platinum elements (A) $(10 \mathrm{mg} / \mathrm{L}$ of $\mathrm{Sn}, \mathrm{Ru}, \mathrm{Rh}, \mathrm{Pd}$, $\mathrm{Sb}, \mathrm{Te}, \mathrm{Hf}$, Ir, $\mathrm{Pt}$, and $\mathrm{Au}$ in $10 \% \mathrm{HCl} / 1 \% \mathrm{HNO}_{3}$ aq.), containing rare earth elements $(\mathbf{B})(10 \mathrm{mg} / \mathrm{L}$ of Sc, Y, La, Ce, Pr, Nd, Sm, $\mathrm{Eu}, \mathrm{Gd}, \mathrm{Tb}, \mathrm{Dy}, \mathrm{Ho}, \mathrm{Er}, \mathrm{Tm}, \mathrm{Yb}, \mathrm{Lu}$, and $\mathrm{Th}$ in $5 \% \mathrm{HNO}_{3}$ aq.), and containing alkali metals, alkali earth metals, typical metals in groups 12-16, $\mathrm{Ag}$, and $\mathrm{U}(\mathrm{C})(10 \mathrm{mg} / \mathrm{L}$ of $\mathrm{Li}, \mathrm{Be}, \mathrm{Na}, \mathrm{Mg}, \mathrm{Al}$, $\mathrm{K}, \mathrm{Ca}, \mathrm{V}, \mathrm{Cr}, \mathrm{Mn}, \mathrm{Fe}, \mathrm{Co}, \mathrm{Ni}, \mathrm{Cu}, \mathrm{Zn}, \mathrm{Ga}$, As, Se, Rb, Sr, Ag, Cd, In, $\mathrm{Cs}, \mathrm{Ba}, \mathrm{Tl}, \mathrm{Pb}, \mathrm{Bi}$, and $\mathrm{U}$ in $5 \% \mathrm{HNO}_{3}$ aq.) (PerkinElmer) were used for competitive adsorption experiments.

2.2. Instruments. IR spectra were recorded on a HORIBA FT-720 spectrometer. Inductive-coupled plasma mass spectrometry (ICP-MS) measurements were performed on a PerkinElmer ELAN DRC II spectrometer. Operating conditions were as follows: nebulizer gas flow, 0.91$1.01 \mathrm{~mL} / \mathrm{min}$; ICP RF power, $1.1 \mathrm{~kW}$; lens voltage, $7.4 \mathrm{~V}$; pulse stage voltage, $900 \mathrm{~V}$; dwell time, $60 \mathrm{~ns}$; sweeps, 3 times; readings per replicate, 3 times; and flow rate, $0.96 \mathrm{~mL} / \mathrm{min}$. The dissolution media for ICP-MS measurements of the samples after metal adsorption experiments were coincided with the multielement solutions, namely, $10 \% \mathrm{HCl}$ aq. for $\mathbf{A}$, $5 \% \mathrm{HNO}_{3}$ aq. for $\mathbf{B}$, and $5 \% \mathrm{HNO}_{3}$ aq. for $\mathbf{C}$.
2.3. Hydrophilic Sulfur-Containing Adsorbent from DTCMMA and NIPAM (1). A solution of DTCMMA ( $96.4 \mathrm{mg}, 442 \mu \mathrm{mol}$ ), NIPAM (500 mg, $4.42 \mathrm{mmol}$ ), MBAA $(6.8 \mathrm{mg}, 4.4 \mu \mathrm{mol})$, and AIBN $(21.8 \mathrm{mg}, 133 \mu \mathrm{mol})$ in DMSO $(3.0 \mathrm{~mL})$ was stirred at $60^{\circ} \mathrm{C}$ for $24 \mathrm{~h}$ under a nitrogen atmosphere. The resulting precipitate was washed with a large amount of methanol and dried under reduced pressure at $50^{\circ} \mathrm{C}$ to obtain a hydrophilic sulfur-containing adsorbent (1) $(586 \mathrm{mg}$, yield $=97.2 \%)$. IR spectra $\left(\mathrm{KBr}, \mathrm{cm}^{-1}\right): 3438(\mathrm{NH}$ in $\left.\mathrm{C}(=\mathrm{O}) \mathrm{NHCH}\left(\mathrm{CH}_{3}\right)_{2}\right), 3303\left(\mathrm{NH}\right.$ in $\left.\mathrm{C}(=\mathrm{O}) \mathrm{NHCH}_{2}\right), 1730$ $\left(\mathrm{C}=\mathrm{O}\right.$ in $\left.\mathrm{C}(=\mathrm{O}) \mathrm{OCH}_{2}\right), 1657(\mathrm{C}=\mathrm{O}$ in $\mathrm{C}(=\mathrm{O}) \mathrm{NH})$, and 1192 $(\mathrm{C}=\mathrm{S})$.

2.4. Hydrophilic Sulfur-Containing Adsorbent from DTCMMA and DMAA (2). A solution of DTCMMA ( $96.4 \mathrm{mg}, 442 \mu \mathrm{mol}$ ), DMAA ( $438 \mathrm{mg}, 4.42 \mathrm{mmol}$ ), MBAA ( $6.8 \mathrm{mg}, 4.4 \mu \mathrm{mol})$, and AIBN (21.8 mg, $133 \mu \mathrm{mol})$ in DMSO $(3.0 \mathrm{~mL})$ was stirred at $60^{\circ} \mathrm{C}$ for $24 \mathrm{~h}$ under a nitrogen atmosphere. The resulting precipitate was washed with a large amount of methanol and dried under reduced pressure at $50^{\circ} \mathrm{C}$ to obtain a hydrophilic sulfur-containing adsorbent (2) $(524 \mathrm{mg}$, yield $=96.8 \%)$. IR spectra $\left(\mathrm{KBr}, \mathrm{cm}^{-1}\right): 3473(\mathrm{NH}$ in $\mathrm{C}(=\mathrm{O}) \mathrm{NH}), 1732\left(\mathrm{C}=\mathrm{O}\right.$ in $\left.\mathrm{C}(=\mathrm{O}) \mathrm{OCH}_{2}\right), 1631(\mathrm{C}=\mathrm{O}$ in $\mathrm{C}$ $\left.(=\mathrm{O}) \mathrm{N}\left(\mathrm{CH}_{3}\right)_{2}, \mathrm{C}(=\mathrm{O}) \mathrm{NH}\right)$, and $1192(\mathrm{C}=\mathrm{S})$.

2.5. Metal Adsorption from Multielement Solution with Hydrophilic Sulfur-Containing Adsorbents (Typical Procedure). A multielement solution $(2.0 \mathrm{~mL}, 10 \mathrm{mg} / \mathrm{L}$ of metal ions) and a hydrophilic sulfur-containing adsorbent $([\mathrm{C}=\mathrm{S}] /[$ total metal $]=4.5 / 1$ ) were stirred in a glass vial at room temperature for $1.5 \mathrm{~h}$. Then, the adsorbent was removed by filtration and washed 2 times with $100 \mathrm{~mL}$ amounts of water. The amounts of adsorbed metals were calculated from the concentrations of metals in the filtrate measured by ICP-MS.

2.6. Competitive Metal Adsorption from $\mathrm{Pd} / \mathrm{Cu}$ Mixed Solution with 2 (Typical Procedure). $\mathrm{CuCl}_{2}(54.9 \mathrm{mg} / \mathrm{mL})$ in $1 \mathrm{~N} \mathrm{HCl}$ solution $(2.0 \mathrm{~mL}), \mathrm{PdCl}_{2}(0.36 \mathrm{mg} / \mathrm{mL})$ in $1 \mathrm{~N} \mathrm{HCl}$ solution $(2.0 \mathrm{~mL})$, and adsorbent $2(50.0 \mathrm{mg})$ were added to a glass vial and stirred at room temperature for $1.5 \mathrm{~h}$. Then, the adsorbent was removed by filtration and washed 2 times with $100 \mathrm{~mL}$ of water. The amounts of adsorbed metals were calculated from the concentrations of metals in the filtrate measured by ICP-MS.

\section{Results and Discussion}

3.1. Synthesis of Hydrophilic Sulfur-Containing Adsorbents. Hydrophilic sulfur-containing adsorbents were synthesized by the radical terpolymerization of DTCMMA, hydrophilic monomer NIPAM or DMAA, and a cross-linker MBAA (feed ratio, [DTCMMA $]_{0}$ : [hydrophilic monomer $]_{0}$ : $\left.[\mathrm{MBAA}]_{0}=9.0: 90.1: 0.90\right)$ in DMSO at $60^{\circ} \mathrm{C}$ using AIBN (2.7 mol\%) under a nitrogen atmosphere (Scheme 1). Products insoluble in common organic solvents and water were obtained in excellent yields. The products obtained using NIPAM and DMAA were denoted as $\mathbf{1}$ and $\mathbf{2}$, 


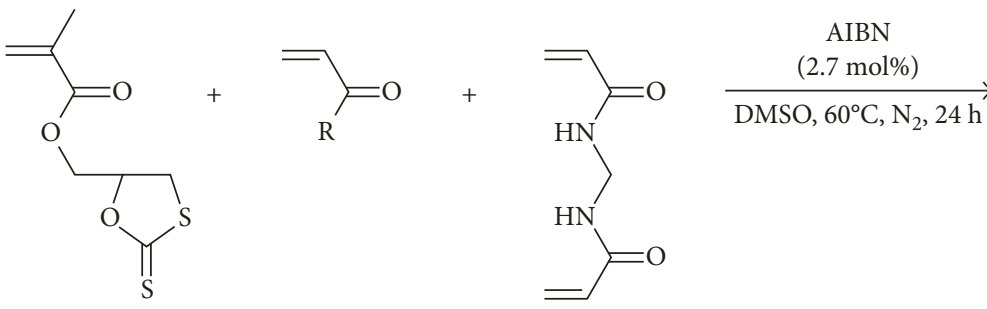

Feed ratio $=9.0: 90.1: 0.9$

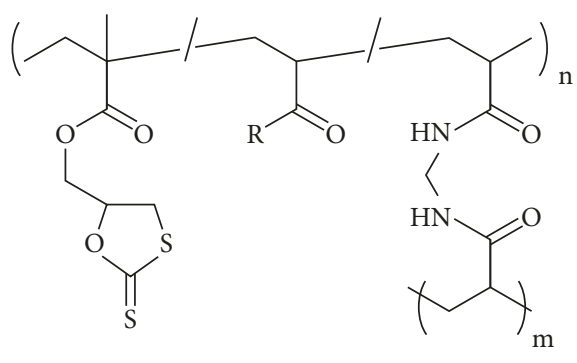

$\mathrm{R}-=\left\{\begin{array}{l}\left(\mathrm{CH}_{3}\right)_{2} \mathrm{CHNH}-(\mathbf{1}) \\ \left(\mathrm{CH}_{3}\right)_{2} \mathrm{~N}-(\mathbf{2})\end{array}\right.$

Scheme 1: Synthesis of hydrophilic sulfur-containing adsorbents $\mathbf{1}$ and $\mathbf{2}$.

(1)

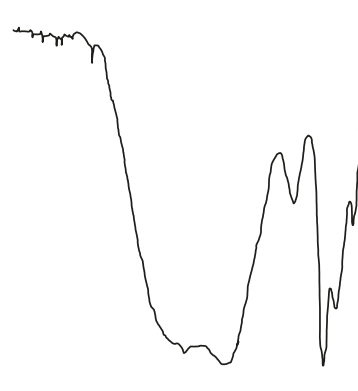

NH : NIPAM, MBAA $(3438-3303)$

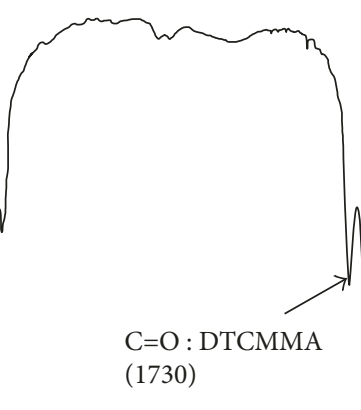

MA

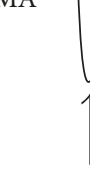

$\mathrm{C}=\mathrm{O}:$

$(1657)$

(2)
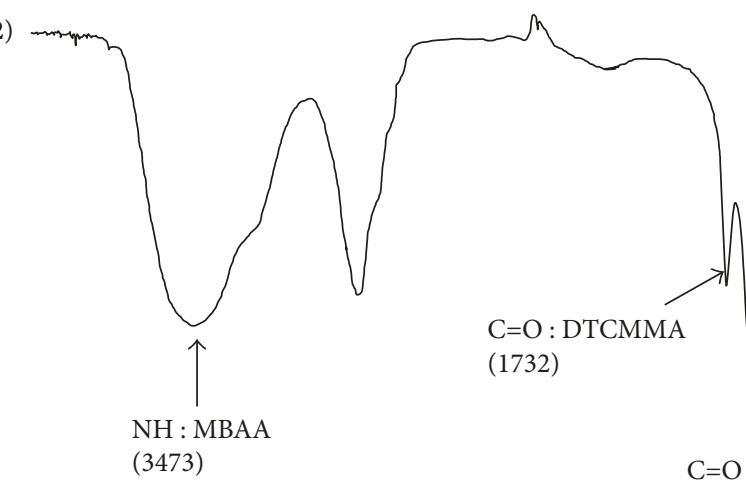
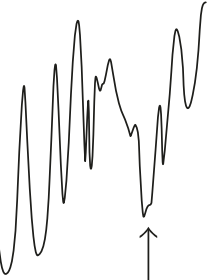

$\uparrow$

$\mathrm{C}=\mathrm{S}: \mathrm{DTCMMA}$

(1192)

DTCMMA NIPAM MBAA

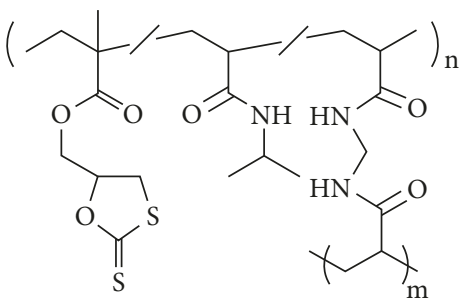

DTCMMA DMAA MBAA<smiles>CCCCC(C)(CCC(C)C(=O)N(C)C)C(=O)OCC1CSC(=S)O1</smiles>

$\uparrow$

$\mathrm{C}=\mathrm{O}:$ DMAA

(1192)

$(1631)$

$\operatorname{U}_{\uparrow} N \operatorname{la}_{\uparrow} \sqrt{ }$

$\mathrm{C}=\mathrm{S}:$ DTCMMA

2000

(1)

FIgURE 1: FT-IR spectra of hydrophilic sulfur-containing adsorbents (1) and (2).

respectively. The products could be swelled by water to yield soft gels. The structures were confirmed by FT-IR spectroscopic analysis (Figure 1). Characteristic peaks assignable to $\mathrm{C}=\mathrm{S}$ moieties in the DTCMMA unit were observed at $1192 \mathrm{~cm}^{-1}$ [60]. Peaks assignable to the amide moieties and carbonyl group in the units originating from the hydrophilic monomers and MBAA were also observed (1: $3438 \mathrm{~cm}^{-1}$ for NH in NIPAM, $3303 \mathrm{~cm}^{-1}$ for NH in MBAA,
$1730 \mathrm{~cm}^{-1}$ for $\mathrm{C}=\mathrm{O}$ in DTCMMA, and $1657 \mathrm{~cm}^{-1}$ for $\mathrm{C}=\mathrm{O}$ in NIPAM; 2: $3473 \mathrm{~cm}^{-1}$ for NH in MBAA, $1732 \mathrm{~cm}^{-1}$ for $\mathrm{C}=\mathrm{O}$ in DTCMMA, and $1631 \mathrm{~cm}^{-1}$ for $\mathrm{C}=\mathrm{O}$ in DMAA). The contents of the DTCMMA unit in the hydrophilic sulfurcontaining adsorbents were estimated by elemental analysis. The contents of DTCMMA units in $\mathbf{1}$ and $\mathbf{2}$ were calculated to be $68.3 \mu \mathrm{mol}$ and $73.0 \mu \mathrm{mol}$ of DTCMMA units per $100 \mathrm{mg}$ of the adsorbents, respectively, which almost agreed 
with the feed ratio (theoretical values for 1 and $2: 73.3$ and $81.6 \mu \mathrm{mol})$.

3.2. Metal Adsorption Experiments to Find the Metals Adsorbed by the Hydrophilic Metal Adsorbents Using Multielement Solutions. The hydrophilic metal adsorbents were used at the molar ratio of $[\mathrm{C}=\mathrm{S}] /[$ total metal $]=4.5 / 1$. The metal adsorption experiments were conducted by dispersing the adsorbents in multielement solutions, and the adsorbents adsorbing metals were separated by filtration. The amounts of the adsorbed metals were calculated by measuring the amounts of the metals in the filtrates by ICP-MS.

The metal adsorption ratios of some metals were calculated to be negative values, possibly because the apparent metal concentrations after the adsorption increased by uptake of water by the adsorbents resulting in increase in the concentration of metals.

First, a multielement solution A was employed for metal adsorption experiments at room temperature for $1.5 \mathrm{~h}$ and $24 \mathrm{~h}$ (Figure 2). As a result, Au was adsorbed almost quantitatively by both of the metal adsorbents in $1.5 \mathrm{~h}$. Pd was also adsorbed quantitatively in $24 \mathrm{~h}$, but the adsorption ratios at $1.5 \mathrm{~h}$ were differed to be 52.3 and $98.7 \%$ for $\mathbf{1}$ and 2 , respectively. The faster adsorption by 2 can be ascribed to the hydrophilicity of the DMAA unit higher than that of the NIPAM unit. Other metals were negligibly adsorbed. The selectivity of the metal adsorption by the sulfur-containing metal adsorbents can be ascribed to the very soft Lewis basicity of the thiocarbonyl group in the dithiocarbonate moieties having high affinity with the very soft Lewis acids Pd and Au.

Second, a multielement solution B was employed for the adsorption at room temperature for $24 \mathrm{~h}$ (Figure 3). As a result, all the adsorption ratios were below $10 \%$. The low adsorption originated from the low affinity between the very soft thiocarbonyl group and the hard rare earth elements.

Third, a multielement solution $\mathbf{C}$ was employed for the adsorption at room temperature for 1.5 and $24 \mathrm{~h}$ (Figure 4). The exact metal concentrations of $\mathrm{Na}, \mathrm{Mg}, \mathrm{Al}, \mathrm{K}, \mathrm{Ca}, \mathrm{Fe}, \mathrm{Zn}$, and $\mathrm{Ba}$ could not be obtained using the standard curves based on this multielement solution, probably due to the leakage of these metals from the vials used in this experiment. As a result, Ag was adsorbed almost quantitatively by both of the metal adsorbents within $1.5 \mathrm{~h}$. Se, originating from $\mathrm{SeO}_{2}$ and existing as selenous acid, was also adsorbed at 36.2 and $31.4 \%$ by $\mathbf{1}$ and 2 , respectively, and the adsorption ratios were increased to ca. $60 \%$ at $24 \mathrm{~h}$. We presume that selenous acid coordinated to the Lewis basic carbonyl groups in $\mathbf{1}$ and $\mathbf{2}$ as a hard Brønsted acid. The selectivity of $\mathbf{1}$ was excellent by the negligible adsorption of other metals, but that of $\mathbf{2}$ was lower due to the slight adsorption of most of the elements, suggesting nonspecific adsorption described later. The experiments using these three multielement solutions proved that the hydrophilic sulfur-containing adsorbents, especially 1, are effective adsorbents for noble metals with high selectivity and efficiency even in the presence of various elements.

We considered the excellent selectivity of the thiocarbonyl group in DTCMMA for noble metals. The

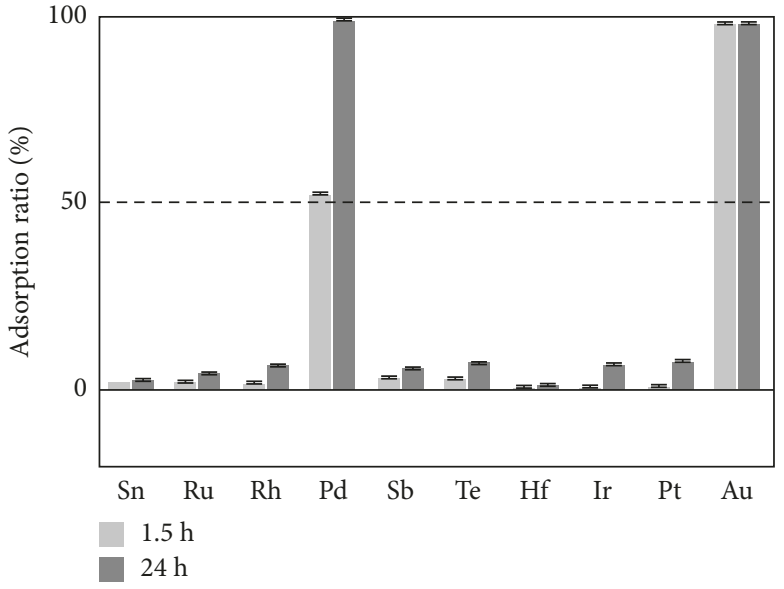

(a)

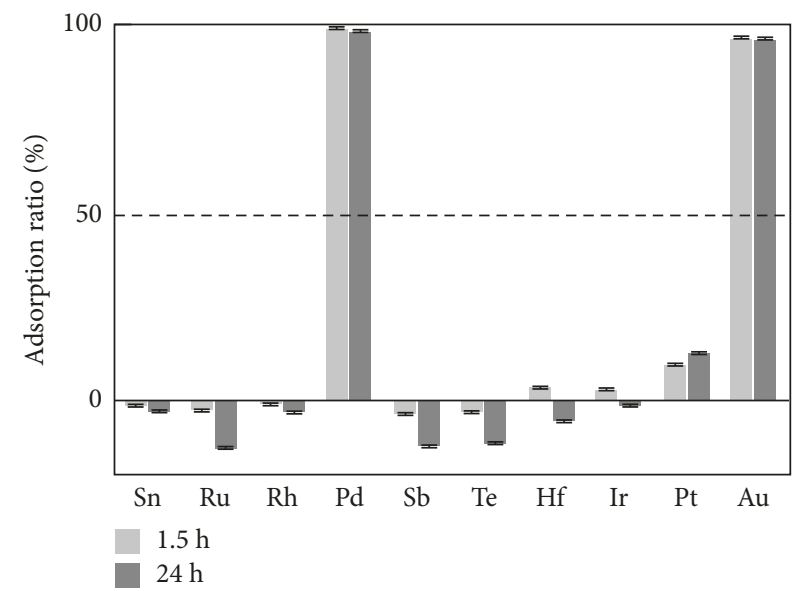

(b)

Figure 2: Metal adsorption from multielement solution A with hydrophilic sulfur-containing adsorbents 1 (a) and 2 (b) (feed molar ratio of $[\mathrm{C}=\mathrm{S}] /[$ total metal $]=4.5 / 1)$.

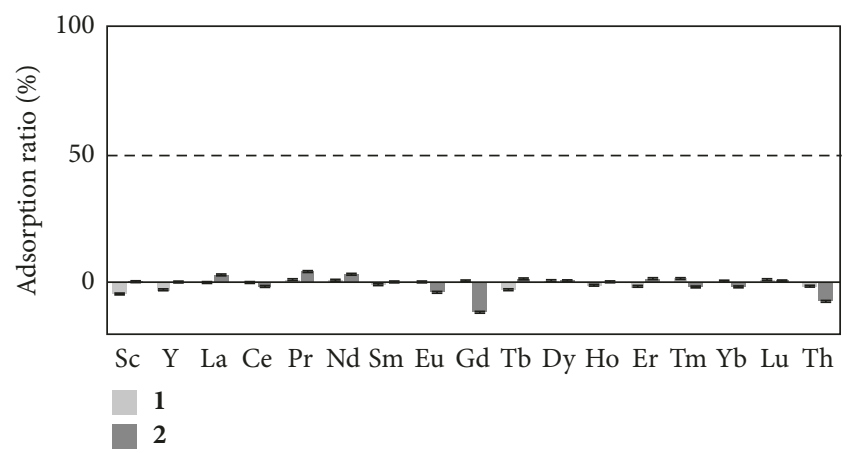

Figure 3: Metal adsorption from multielement solution $\mathbf{B}$ with hydrophilic sulfur-containing adsorbents $\mathbf{1}$ and $\mathbf{2}$ (feed molar ratio of $[\mathrm{C}=\mathrm{S}] /[$ total metal $]=4.5 / 1)$.

selectivity of $\mathbf{1}$ and $\mathbf{2}$ toward $\mathrm{Pd}, \mathrm{Au}$, and $\mathrm{Ag}$ is higher than conventional adsorbents having thiocarbonyl groups such as thioamide [26-30, 46-52], thiourethane [32, 34, 36], and thiourea [11, 25, 53-59] including a commercial adsorbent QuadraPure ${ }^{\mathrm{TM}} \mathrm{TU}$ (Aldrich) with the $\mathrm{R}-\mathrm{NH}(\mathrm{C}=\mathrm{S}) \mathrm{NH}_{2}$ 


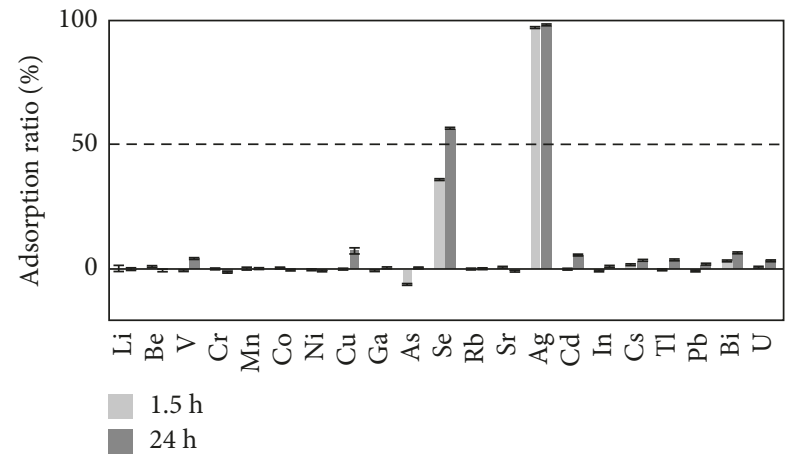

(a)

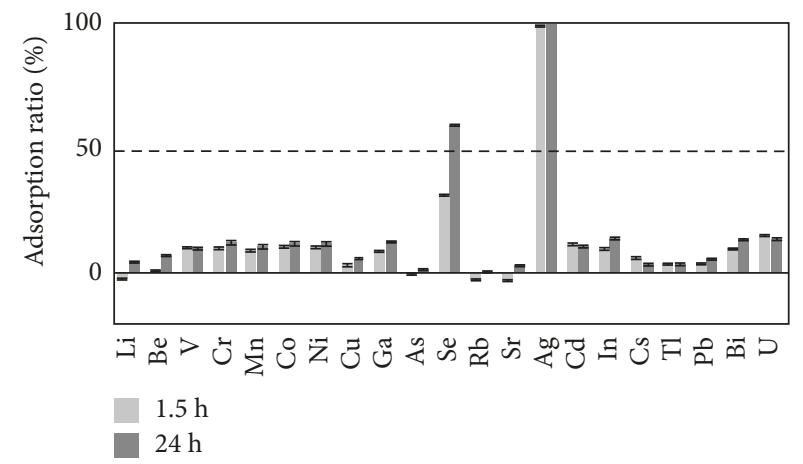

(b)

FIgURe 4: Metal adsorption from multielement solution $\mathbf{C}$ with hydrophilic sulfur-containing adsorbents $\mathbf{1}$ (a) and $\mathbf{2}$ (b) (feed molar ratio of $[\mathrm{C}=\mathrm{S}] /[$ total metal $]=4.5 / 1)$.

structure [61]. The lower selectivity of these thiocarbonyl structures can be ascribed to the tautomerism between thiocarbonyl and thiol. For example, the thiourea structure in QuadraPure TU can take the tautomeric iminothiol structure (Scheme 2) [62]. The thiol group is a harder ligand than the thiocarbonyl group and has higher affinity with metals with harder Lewis acidity. By contrast, the selectivity of DTCMMA for the noble metals is higher by the dithiocarbonate moiety without taking harder tautomeric structures.

\subsection{Control Experiment Using Cross-Linked Polymers without} DTCMMA Unit. We confirmed the effect of the DTCMMA unit using analogous cross-linked polymers without DTCMMA unit. The cross-linked polymers were synthesized by the radical copolymerization of the hydrophilic monomers NIPAM $\left(\mathbf{1}^{\prime}\right)$ and DMAA $\left(\mathbf{2}^{\prime}\right)$ with MBAA in DMSO at $60^{\circ} \mathrm{C}$ under a nitrogen atmosphere. Control experiments with $\mathbf{1}^{\prime}$ and $\mathbf{2}^{\prime}$ were conducted using the multielement solutions $\mathbf{A}$ and $\mathbf{C}$, which contain the metals adsorbed by $\mathbf{1}$ and $\mathbf{2}$. The metal adsorption experiments were conducted at room temperature for $24 \mathrm{~h}$ in a similar manner with the adsorption experiments using the sulfur-containing adsorbents. Most of the elements in A were hardly adsorbed as the cases of $\mathbf{1}$ and $\mathbf{2}$, but the adsorption ratios of Au by $\mathbf{1}^{\prime}$ and $\mathbf{2}^{\prime}$ were slightly higher $(19.0 \%$ and $16.7 \%$, resp.) (Figure 5). A plausible reason for the adsorption of $\mathrm{Au}$ is the adsorption with the amide moieties as reported for poly (NIPAM), poly(DMAA), and poly( $N, N$-diethylacrylamide) gels [63], which should be occurred for the amide moieties in $\mathbf{1}^{\prime}$ and $\mathbf{2}^{\prime}$ leading to the nonspecific adsorption. In the adsorption from the multielement solution $\mathbf{C}, \mathbf{1}^{\prime}$ negligibly adsorbed metals, indicating that nonspecific adsorption is ignorable (Figure 6). Contrary to $\mathbf{1}^{\prime}, \mathbf{2}^{\prime}$ adsorbed most of the metals though to lesser expects. These control experiments supported the excellent selectivity of $\mathbf{1}$ toward noble metals than 2. A possible reason is the harder Lewis basicity of the carbonyl group in DMAA units that is likely to be responsible for nonspecific adsorption. The difference in the Lewis basicity was supported by FT-IR absorption of the carbonyl groups in $\mathbf{1}^{\prime}$ and $\mathbf{2}^{\prime}$ appeared at $1635 \mathrm{~cm}^{-1}$ and

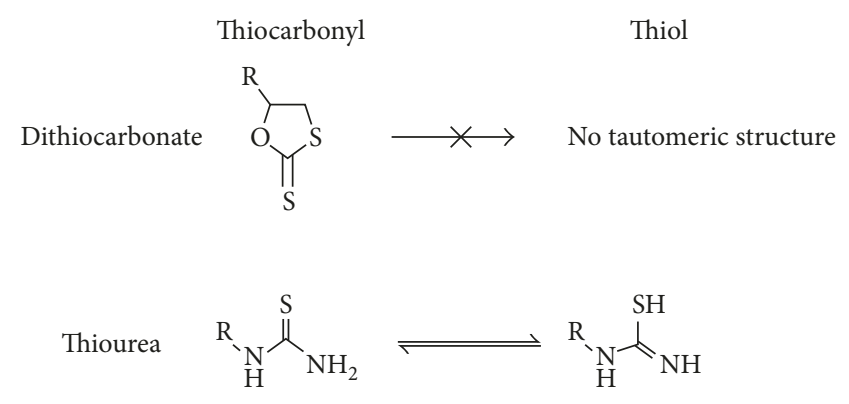

Scheme 2: Tautomeric structures of thiocarbonyl and thiol.

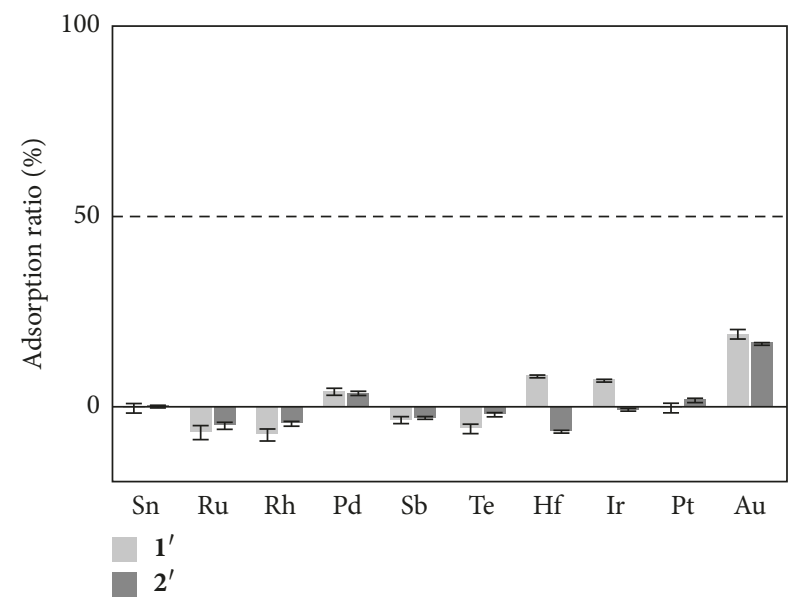

FIgUre 5: Metal adsorption from multielement solution $\mathbf{A}$ with hydrophilic gels $\mathbf{1}^{\prime}$ and $\mathbf{2}^{\prime}$.

$1610 \mathrm{~cm}^{-1}$, respectively. This result convinced us that the DTCMMA unit in the sulfur-containing adsorbents served as the important group for adsorption of noble metals.

3.4. Competitive Metal Adsorption from Mixed Solution of Pd and Excess Amount of $\mathrm{Cu}$ by 2 . Pd is a noble metal, and the concentration in nature is very low. In addition to the content in Pd mines, Pd is slightly contained in ores of other metals such as $\mathrm{Cu}$. In industrial and catalytic uses of Pd, Pd are often 


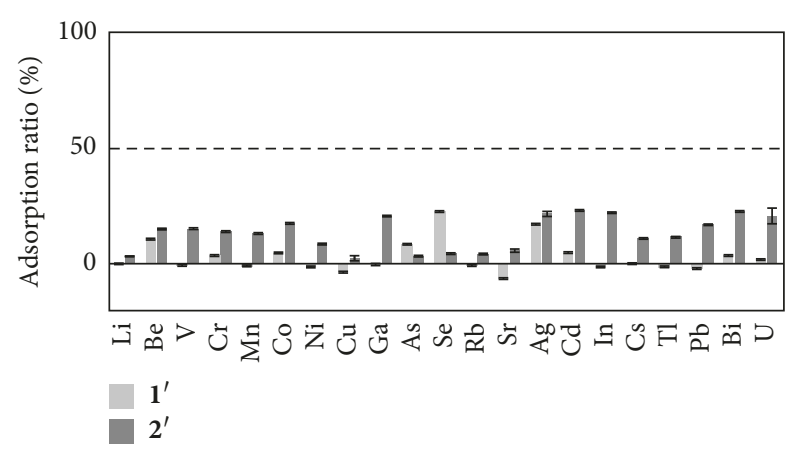

FIgURE 6: Metal adsorption from multielement solution $\mathbf{C}$ with hydrophilic gels $\mathbf{1}^{\prime}$ and $\mathbf{2}^{\prime}$.

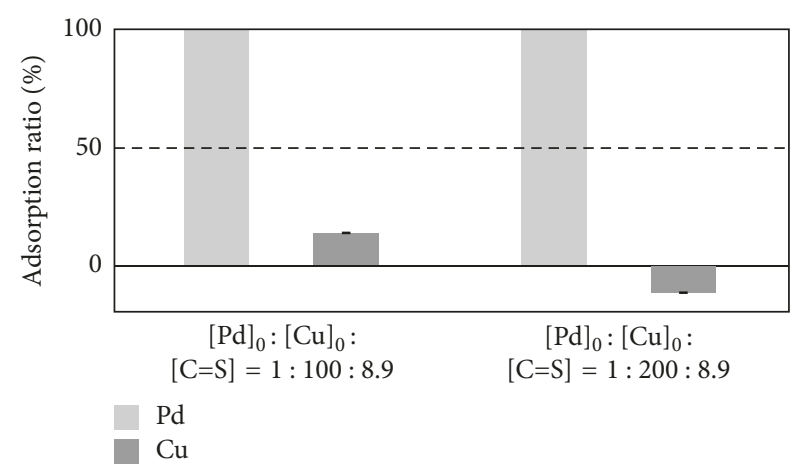

Figure 7: Competitive metal adsorption from mixed solutions of $\mathrm{Pd}$ and excess amount of $\mathrm{Cu}$ by 2 .

used with other metals such as catalysts for Sonogashira coupling reaction combined with copper halides [64]. For this reason, extraction of Pd from mixtures containing excess amounts of other metals such as $\mathrm{Cu}$ is an important subject. Accordingly, we conducted competitive adsorption experiments for Pd from mixtures containing excess amounts of $\mathrm{Cu}$ with $\mathbf{2}$. The feed molar ratios of the $\mathrm{C}=\mathrm{S}$ moieties in $\mathbf{2}$ and the metals examined were $[\mathrm{C}=\mathrm{S}]:[\mathrm{Pd}]_{0}:[\mathrm{Cu}]_{0}=8.9: 1: 100$ and $8.9: 1: 200$. The experiment was conducted for $1.5 \mathrm{~h}$ in a similar manner with the case of the multielement solutions. As a result, 2 adsorbed Pd in an effective and selective manner at both of the feed ratios in spite of the excess amounts of $\mathrm{Cu}$ (Figure 7). This result suggested the excellent selectivity of 2 as a Pd adsorption agent from solutions containing various base metals such as wastewater from $\mathrm{Cu}$ mines and waste solutions after Pd-catalyzed reactions [65].

\section{Conclusions}

We developed hydrophilic sulfur-containing adsorbents having thiocarbonyl groups based on a methacrylate bearing dithiocarbonate moieties and investigated the effect of the structure adjacent to the thiocarbonyl group. The hydrophilic sulfur-containing adsorbents $\mathbf{1}$ and $\mathbf{2}$ could selectively adsorb noble metals, $\mathrm{Au}, \mathrm{Ag}$, and $\mathrm{Pd}$, from multielement aqueous solutions $\mathbf{A}$ and $\mathbf{B}$. Au and $\mathrm{Ag}$ were adsorbed within $1.5 \mathrm{~h}$ by $\mathbf{1}$ and 2 . The adsorption of Pd from multielement solution A with $\mathbf{2}$ proceeded faster than $\mathbf{1}$ owing to the higher hydrophilicity of DMAA than NIPAM but 1 also quantitatively adsorbed Pd for $24 \mathrm{~h}$. Selective adsorption of Pd could be achieved with 2 in the presence of excess amounts of $\mathrm{Cu}$ by the high noble metal selectivity. The selectivity of $\mathbf{1}$ to noble metals was higher than $\mathbf{2}$ due to the lower nonspecific adsorption. The high selectivity of the hydrophilic sulfur-containing adsorbents is advantageous for practical recycling of noble metals from industrial and mining wastewater.

\section{Conflicts of Interest}

The authors declare that they have no conflicts of interest.

\section{Acknowledgments}

The authors are grateful for the financial supports from the Academia Showcase from Japan Chemical Innovation and Inspection Institute and the Grant-in-Aid for Scientific Research for Rare Metals Recycling from the Ministry of the Environment in Japan (K22030). The authors are also grateful to Dr. Atsushi Sasaki of Faculty of Engineering of Yamagata University for his kind suggestion and instruction on ICP-MS measurements.

\section{References}

[1] J. H. Potgieter, S. S. Potgieter, R. K. K. Mbaya, and A. Teodorovic, "Small scale recovery of noble metals from jewellery wastes," Journal of the SA Institute of Mining \& Metallurgy, vol. 104, pp. 563-571, 2004.

[2] N. Miyaura and A. Suzuki, "Palladium-catalyzed crosscoupling reactions of organoboron compounds," Chemical Reviews, vol. 95, no. 7, pp. 2457-2483, 1995.

[3] M. S. Hegde, G. Madras, and K. C. Patil, "Noble metal ionic catalysts," Accounts of Chemical Research, vol. 42, no. 6, pp. 704-712, 2009.

[4] S. D. Lin and C. Song, "Noble metal catalysts for lowtemperature naphthalene hydrogenation in the presence of benzothiophene," Catalysis Today, vol. 31, no. 1-2, pp. 93-104, 1996.

[5] P. Gelin and M. Primet, "Complete oxidation of methane at low temperature over noble metal based catalysts: a review," Applied Catalysis B: Environmental, vol. 39, no. 1, pp. 1-37, 2002.

[6] J. Cui and E. Forssberg, "Mechanical recycling of waste electric and electronic equipment: a review," Journal of Hazardous Materials, vol. 99, no. 3, pp. 243-263, 2003.

[7] M. Faisai, Y. Atsuta, H. Daimon, and K. Fujie, "Recovery of precious metals from spent automobile catalytic converters using supercritical carbon dioxide," Asia-Pacific Journal of Chemical Engineering, vol. 3, no. 4, pp. 364-367, 2008.

[8] N. T. Hung, M. Watanabe, and T. Kimura, "Solvent extraction of palladium(II) with various ketones from nitric acid medium," Solvent Extraction and Ion Exchange, vol. 25, no. 3, pp. 407-416, 2007.

[9] J. S. Wang and C. M. Wai, "Dissolution of precious metals in supercritical carbon dioxide," Industrial \& Engineering Chemistry Research, vol. 44, no. 4, pp. 922-926, 2005.

[10] E. Lachowicz, B. Rozanska, F. Teixidor, H. Meliani, M. Barboiu, and N. Hovnanian, "Comparison of sulphur and sulphur-oxygen ligands as ionophores for liquid-liquid 
extraction and facilitated transport of silver and palladium," Journal of Membrane Science, vol. 210, no. 2, pp. 279-290, 2002.

[11] T. Kai, T. Hagiwara, H. Haseba, and T. Takahashi, "Reduction of thiourea consumption in gold extraction by acid thiourea solutions," Industrial \& Engineering Chemistry Research, vol. 36, no. 7, pp. 2757-2759, 1997.

[12] J. S. Preston and A. C. du Preez, "The separation of europium from a middle rare earth concentrate by combined chemical reduction, precipitation and solvent-extraction methods," Journal of Chemical Technology \& Biotechnology, vol. 65, no. 1, pp. 93-101, 1996.

[13] C. S. Griffith, V. Luca, J. V. Hanna, K. J. Pike, M. K. Smith, and G. S. Thorogood, "Microcrystalline hexagonal tungsten bronze. 1. basis of ion exchange selectivity for cesium and strontium," Inorganic Chemistry, vol. 48, no. 13, pp. 5648-5662, 2009.

[14] D. Y. Zuo, B. K. Zhu, S. H. Wang, and Y. Y. Xu, "Membrane extraction for separation of copper cations from acid solution using polypropylene hollow fibre membrane," Polymers for Advanced Technologies, vol. 16, no. 10, pp. 738-743, 2005.

[15] A. Kargari, T. Kaghazchi, and M. Soleimani, "Extraction of gold (III) ions from aqueous solutions using polyamine type surfactant liquid membrane," Canadian Journal of Chemical Engineering, vol. 82, no. 6, pp. 1301-1306, 2004.

[16] W. S. W. Ho, B. Wang, T. E. Neumuller, and J. Roller, "Supported liquid membranes for removal and recovery of metals from waste waters and process streams," Environmental Progress, vol. 20, no. 2, pp. 117-121, 2001.

[17] E. R. Els, L. Lorenzen, and C. Aldrich, "The adsorption of precious metals and base metals on a quaternary ammonium group ion exchange resin," Minerals Engineering, vol. 13, no. 4, pp. 401-414, 2000.

[18] D. Clifford and W. J. Weber, "The determinants of divalent/ monovalent selectivity in anion exchangers," Reactive Polymers, Ion Exchangers, Sorbents, vol. 1, no. 2, pp. 77-89, 1983.

[19] Q. Xu, P. Yin, G. Zhao, Y. Sun, and R. Qu, "Character of longchain branching in highly purified natural rubber," Journal of Applied Polymer Science, vol. 117, no. 6, pp. 3645-3650, 2010.

[20] K. Deplanche, R. D. Woods, I. P. Mikheenko, R. E. Sockett, and L. E. Macaskie, "Manufacture of stable palladium and gold nanoparticles on native and genetically engineered flagella scaffolds," Biotechnology and Bioengineering, vol. 101, no. 5, pp. 873-880, 2008.

[21] C. R. Adhikari, D. Parajuli, H. Kawakita, K. Inoue, K. Ohto, and H. Harada, "Dimethylamine-modified waste paper for the recovery of precious metals," Environmental Science \& Technology, vol. 42, no. 15, pp. 5486-5491, 2008.

[22] S. Kiyoyama, T. Maruyama, N. Kamiya, and M. Goto, "Immobilization of proteins into microcapsules and their adsorption properties with respect to precious-metal ions," Industrial \& Engineering Chemistry Research, vol. 47, no. 5, pp. 1527-1532, 2008.

[23] L. Wan, Y. Wang, and S. Qian, "Study on the adsorption properties of novel crown ether crosslinked chitosan for metal ions," Journal of Applied Polymer Science, vol. 84, no. 1, pp. 29-34, 2002.

[24] J. M. Sanchez, M. Hidalgo, and V. Salvado, "The selective adsorption of gold (III) and palladium (II) on new phosphine sulphide-type chelating polymers bearing different spacer arms," Reactive and Functional Polymers, vol. 46, no. 3, pp. 283-291, 2001.

[25] G. Zuo and M. Muhammed, "Thiourea-based coordinating polymers: synthesis and binding to noble metals," Reactive Polymers, vol. 24, no. 3, pp. 165-181, 1995.
[26] K. Okamoto, T. Kanbara, T. Yamamoto, and A. Wada, "Preparation and characterization of luminescent SCS and NCN pincer platinum complexes derived from 3,5-bis(anilinothiocarbonyl)toluene," Organometallics, vol. 25, no. 16, pp. 4026-4029, 2006.

[27] M. Akaiwa, T. Kanbara, H. Fukumoto, and T. Yamamoto, "Luminescent palladium complexes containing thioamidebased SCS pincer ligands," Journal of Organometallic Chemistry, vol. 690, no. 18, pp. 4192-4196, 2005.

[28] T. Koizumi, T. Teratani, K. Okamoto, T. Yamamoto, Y. Shimoi, and T. Kanbara, "Nickel(II) complexes bearing a pincer ligand containing thioamide units: comparison between SNS- and SCS-pincer ligands," Inorganica Chimica Acta, vol. 363, no. 11, pp. 2474-2480, 2010.

[29] J. Kuwabara and T. Kanbara, "Synthesis and optical properties of pincer palladium and platinum complexes having thioamide units," Journal of Photopolymer Science and Technology, vol. 21, no. 3, pp. 349-353, 2008.

[30] S. Kagaya, E. Sato, I. Masore, K. Hasegawa, and T. Kanbara, "Polythioamide as a collector for valuable metals from aqueous and organic solutions," Chemistry Letters, vol. 32, no. 7, pp. 622-623, 2003.

[31] M. K. M. Z. Hyder and B. Ochiai, "Synthesis of a selective scavenger for $\mathrm{Ag}(\mathrm{I}), \mathrm{Pd}(\mathrm{II})$, and $\mathrm{Au}(\mathrm{III})$ based on cellulose filter paper grafted with polymer chains bearing thiocarbamate moieties," Chemistry Letters, vol. 46, no. 4, pp. 492-494, 2017.

[32] M. Spitzer and R. Bertazzoli, "Selective electrochemical recovery of gold and silver from cyanide aqueous effluents using titanium and vitreous carbon cathodes," Hydrometallurgy, vol. 74, no. 3-4, pp. 233-242, 2004.

[33] D. Nagai, T. Imazeki, H. Morinaga, H. Oku, and K. Kasuya, "Three-component polyaddition of diamines, carbon disulfide, and diacrylates in water," Journal of Polymer Science Part A: Polymer Chemistry, vol. 48, no. 4, pp. 845-851, 2010.

[34] S. Kagaya, H. Miyazaki, M. Ito, K. Tohda, and T. Kanbara, "Selective removal of mercury(II) from wastewater using polythioamides," Journal of Hazardous Materials, vol. 175, no. 1-3, pp. 1113-1115, 2010.

[35] B. Ochiai, T. Ogihara, M. Mashiko, and T. Endo, "Synthesis of rare-metal absorbing polymer by three-component polyaddition through combination of chemo-selective nucleophilic and radical additions," Journal of the American Chemical Society, vol. 131, no. 5, pp. 1636-1637, 2009.

[36] W. Yantasee, C. L. Warner, T. Sangvanich et al., "Removal of heavy metals from aqueous systems with thiol functionalized superparamagnetic nanoparticles," Environmental Science \& Technology, vol. 41, no. 14, pp. 5114-5119, 2007.

[37] D. Nagai, T. Imazeki, H. Morinaga, and H. Nakabayashi, "Synthesis of a rare-metal adsorbing polymer by threecomponent polyaddition of diamines, carbon disulfide, and diacrylates in an aqueous/organic biphasic medium," Journal of Polymer Science Part A: Polymer Chemistry, vol. 48, no. 24, pp. 5968-5973, 2010.

[38] A. Ramesh, K. R. Mohan, and K. Seshaiah, "Announcement," Talanta, vol. 57, no. 2, pp. 243-252, 2002.

[39] G. D. Thorn and R. A. Ludwig, The Dithiocarbamates and Related Compounds, Elsevier Co., Amsterdam, Netherlands, 1962.

[40] B. Biannic, T. Ghebreghiorgis, and A. Aponick, "A comparative study of the Au-catalyzed cyclization of hydroxysubstituted allylic alcohols and ethers," Beilstein Journal of Organic Chemistry, vol. 7, pp. 802-807, 2011.

[41] G. Li, Z. Zhao, J. Liu, and G. Jiang, "Effective heavy metal removal from aqueous systems by thiol functionalized 
magnetic mesoporous silica," Journal of Hazardous Materials, vol. 192, pp. 277-283, 2011.

[42] J. M. Richardson and C. W. Jones, "Strong evidence of solution-phase catalysis associated with palladium leaching from immobilized thiols during Heck and Suzuki coupling of aryl iodides, bromides, and chlorides," Journal of Catalysis, vol. 251, pp. 80-93, 2007.

[43] M. Yu, W. Tian, D. Sun, W. Shen, G. Wang, and N. Xu, "Systematic studies on adsorption of 11 trace heavy metals on thiol cotton fiber," Analytica Chimica Acta, vol. 428, no. 2, pp. 209-218, 2001.

[44] I. L. Lagadic, M. K. Mitchell, and B. D. Payne, "Highly effective adsorption of heavy metal ions by a thiolfunctionalized magnesium phyllosilicate clay," Environmental Science \& Technology, vol. 35, no. 5, pp. 984-990, 2001.

[45] G. Hernandez and R. Rodriguez, "Adsorption properties of silica sols modified with thiol groups," Journal of NonCrystalline Solids, vol. 246, no. 3, pp. 209-215, 1999.

[46] A. Lezzi, S. Cobianco, and A. Roggero, "Synthesis of thiol chelating resins and their adsorption properties toward heavy metal ions," Journal of Polymer Science Part A: Polymer Chemistry, vol. 32, no. 10, pp. 1877-1883, 1994.

[47] P. D. Akrivos, "Recent studies in the coordination chemistry of heterocyclic thiones and thionates," Coordination Chemistry Reviews, vol. 213, no. 1, pp. 181-210, 2001.

[48] B. Slootmaekers, E. Manessi-Zoupa, S. P. Perlepes, and H. O. Desseyn, "The infrared spectra of complexes with planar dithiooxamides part VIII. The Au(III) complexes," Spectrochimica Acta Part A: Molecular and Biomolecular Spectroscopy, vol. 52, no. 10, pp. 1255-1273, 1996.

[49] S. H. J. De Beukeleer and H. O. Desseyn, "Vibrational analysis of some transition metal complexes with deprotonated and neutral malonamide," Spectrochimica Acta Part A: Molecular Spectroscopy, vol. 51, no. 14, pp. 1617-1633, 1995.

[50] E. S. Raper, "Copper complexes of heterocyclic thioamides and related ligands," Coordination Chemistry Reviews, vol. 129, no. 1-2, pp. 91-156, 1994.

[51] C.-Y. Liu, H.-T. Chang, and C.-C. Hu, "Complexation reactions in a heterogeneous system," Inorganica Chimica Acta, vol. 172, no. 2, pp. 151-158, 1990.

[52] R. L. Martin and A. F. Masters, "Thio derivatives of 1,3diketones and their metal complexes. Dithiomalonamide and its nickel(II), palladium(II), and platinum(II) derivatives," Inorganic Chemistry, vol. 14, no. 4, pp. 885-892, 1975.

[53] R. W. Kluiber, "Inner complexes. V. copper(II) and nickel(II) chelates of $\mathrm{N}$-alkylthiopicolinamides," Inorganic Chemistry, vol. 4, no. 6, pp. 829-833, 1965.

[54] Y. Jiang, H. Zhang, Q. He, and Z. Hu, "Selective solid-phase extraction of trace mercury(II) using a silica gel modified with diethylenetriamine and thiourea," Microchimica Acta, vol. 178, no. 3-4, pp. 421-428, 2012.

[55] M. J. Girgis, L. E. Kuczynski, S. M. Berberena et al., "Removal of soluble palladium complexes from reaction mixtures by fixed-bed adsorption," Organic Process Research \& Development, vol. 12, no. 6, pp. 1209-1217, 2008.

[56] T. Mikysek, I. Svancara, K. Vytras, and F. G. Banica, "Functionalised resin-modified carbon paste sensor for the voltammetric determination of $\mathrm{Pb}$ (II) within a wide concentration range," Electrochemistry Communications, vol. 10, no. 2, pp. 242-245, 2008.

[57] A. Hinchcliffe, C. Hughes, D. A. Pears, and M. R. Pitts, "QuadraPure cartridges for removal of trace metal from reaction mixtures in flow," Organic Process Research \& Development, vol. 11, no. 3, pp. 477-481, 2007.
[58] N. Nikbin, M. Ladlow, and S. V. Ley, "Continuous flow ligand-free heck reactions using monolithic Pd [0] nanoparticles," Organic Process Research \& Development, vol. 11, no. 3, pp. 458-462, 2007.

[59] C. Ni, C. Yi, and Z. Feng, "Studies of syntheses and adsorption properties of chelating resin from thiourea and formaldehyde," Journal of Applied Polymer Science, vol. 82, no. 13, pp. 3127-3132, 2001.

[60] H. A. Abd El-Rehim, E. A. Hegazy, and A. El-Hag Ali, "Selective removal of some heavy metal ions from aqueous solution using treated polyethylene-g-styrene/maleic anhydride membranes," Reactive and Functional Polymers, vol. 43, no. 1-2, pp. 105-116, 2000.

[61] N. Kihara, H. Tochigi, and T. Endo, "Synthesis and reaction of polymers bearing 5-membered cyclic dithiocarbonate group," Journal of Polymer Science Part A: Polymer Chemistry, vol. 33, pp. 1005-1010, 1995.

[62] G. A. A. Al-Hazmi, A. A. El-Zahhar, K. S. Abou-Melha et al., "Elaborated spectral analysis and modeling calculations on $\mathrm{Co}(\mathrm{II}), \mathrm{Ni}(\mathrm{II}), \mathrm{Cu}(\mathrm{II}), \mathrm{Pd}(\mathrm{II}), \mathrm{Pt}(\mathrm{II})$, and $\mathrm{Pt}(\mathrm{IV})$ nanoparticles complexes with simple thiourea derivative," Journal of Coordination Chemistry, vol. 68, no. 6, pp. 993-1009, 2015.

[63] H. Rostkowska, L. Lapinski, A. Khvorostov, and M. J. Nowak, "Proton-transfer processes in thiourea: UV induced thione $\rightarrow$ thiol reaction and ground state thiol $\rightarrow$ thione tunneling," Journal of Physical Chemistry A, vol. 107, no. 33, pp. 63736380, 2003.

[64] H. Tokuyama and A. Kanehara, "Temperature swing adsorption of gold(III) ions on poly(N-isopropylacrylamide) gel," Reactive and Functional Polymers, vol. 67, no. 2, pp. 136-143, 2007.

[65] K. Sonogashira, Y. Tohda, and N. Hagihara, "A convenient synthesis of acetylenes: catalytic substitutions of acetylenic hydrogen with bromoalkenes, iodoarenes and bromopyridines," Tetrahedron Letters, vol. 16, no. 50, pp. 4467-4470, 1975. 


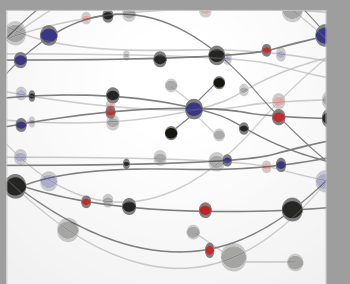

The Scientific World Journal
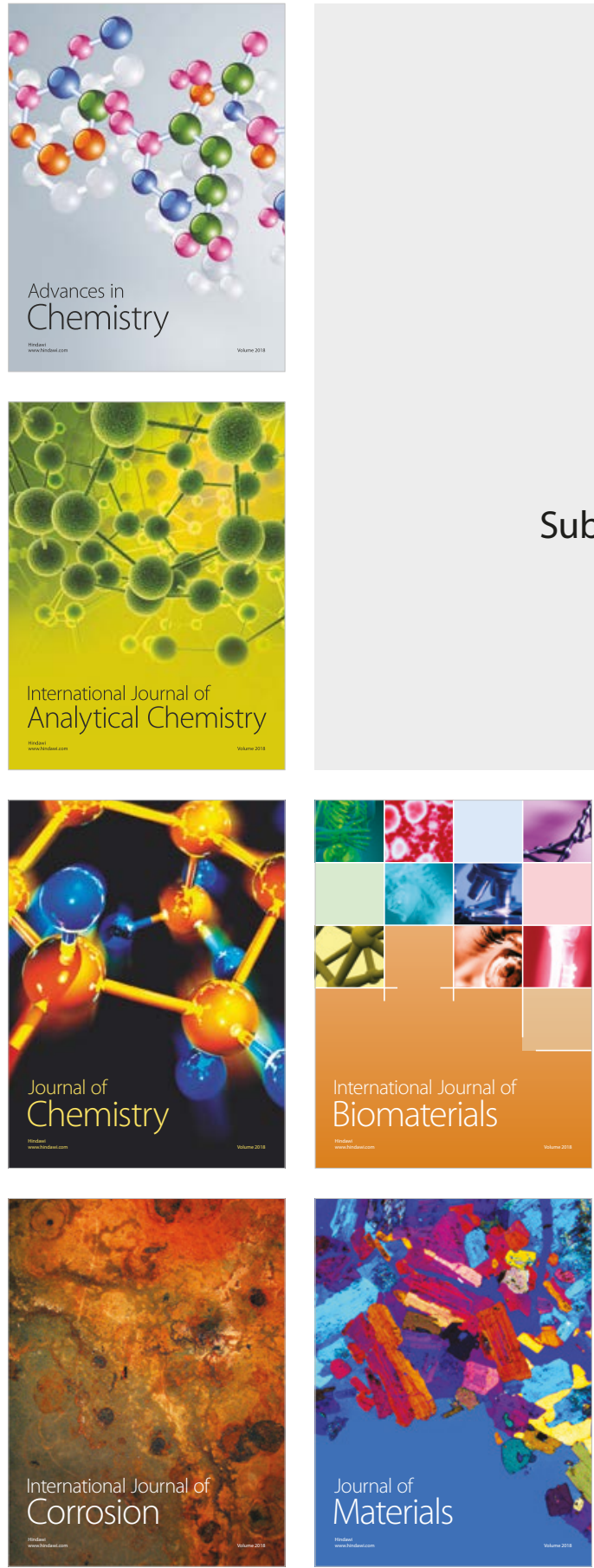

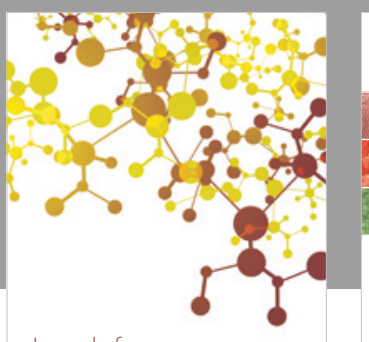

Journal of

Applied Chemistry
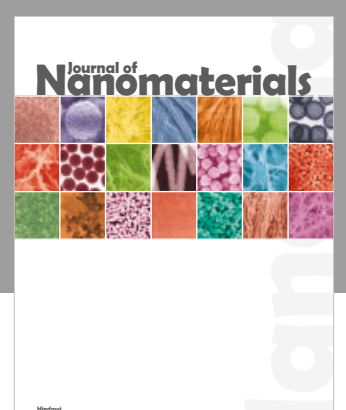

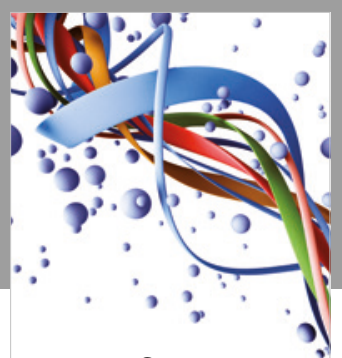

Scientifica

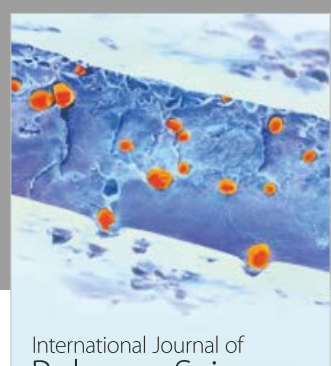

Polymer Science

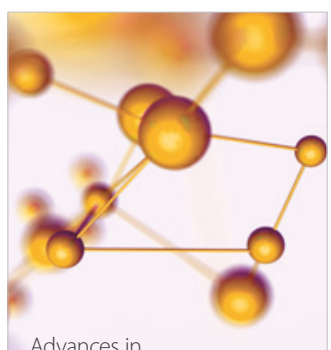

Physical Chemistry
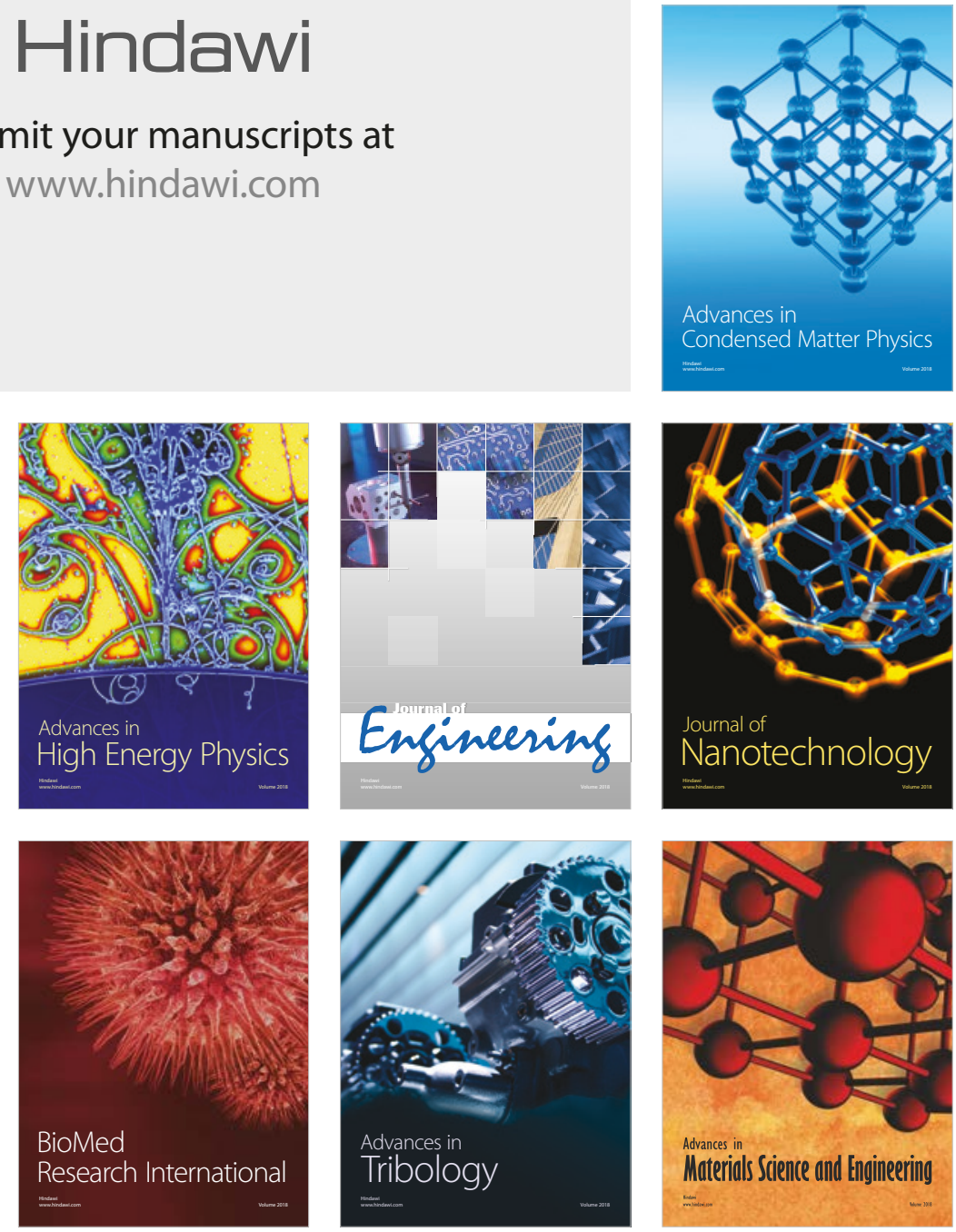